\title{
Starter Dietary Lysine Level and Strain Cross Effects on Performance and Carcass Traits of Broiler Females ${ }^{1,2}$
}

Author(s)

Corzo A

Kidd MT

Department of Poultry Science

Mississippi State University

Mississippi State, MS 39762

Mail Address

Michael T. Kidd

Department of Poultry Science

Mississippi State University

Box 9665

Mississippi State. MS 39762-9665

Phone: 6623255430

Ffax: $\quad 6623258292$

E-mail:mkidd@poultry.msstate.edu

\section{Keywords}

Breast meat, broiler, lysine, performance.

\section{ABSTRACT}

Dietary lysine has been shown to impact the performance of broilers, particularly with aspect of breast meat accretion and yield. There have been studies that suggest that early dietary lysine has an effect on breast meat yield in male broilers. A study was designed to evaluate starter dietary lysine (1.20 vs $1.35 \%$ of diet as achieved by the addition of Llysine at the expense of a filler) effect on performance of female broilers from three different genetic strain crosses, and monitor subsequent effects at 41 and $56 \mathrm{~d}$ of age.

Body weight and feed consumption were higher for birds consuming the high lysine starter diet, but feed conversions were similar when compared to the low lysine diet. Body weight and feed conversion were similar among strains. Mortality was unaffected by lysine level and strain cross. Carcass and breast meat weight, but not yields, were higher in birds fed the high lysine diet. At $56 \mathrm{~d}$ differences in carcass yield, abdominal fat, and breast meat yield were seen among strains, such that the strain with highest yield had the least amount of abdominal fat in terms of absolute weight and percentage. No effect on processing yields by dietary lysine was observed at any time regardless of the growing characteristics of the broilers. However, for early slaughter ages, feeding high levels of dietary lysine during the starter phase could prove to be convenient when maximum live performance or breast meat absolute values are desiredin order to maintain the commercial quality of final products.

\section{INTRODUCTION}

Lysine needs of starting chicks (up to Day 21) have been studied extensively (Schwartz et al., 1958; Hewitt \& Lewis, 1972; McNaughton et al., 1977; Han \& Baker, 1991; Han \& Baker, 1993). Different recommended levels of dietary lysine have been determined across laboratories because numerous variations have existed among experiments (e.g., genetic strain, environmental temperature, feed ingredients, protein source and quality, and sex (Han \& Baker, 1991; Han \& Baker, 1993). It has been shown that current NRC (1994) recommendations for lysine up to d 21 are too low for today's commercial broiler (Han \& Baker, 1991; Vasquez \& Pesti, 1997; Kidd \& Fancher, 2001). Furthermore, recent studies have shown an increase in performance when dietary lysine during the starter phase is higher than recommended levels (Kidd et al., 1998; Kidd \& Fancher, 2001). Such effects were observed for the Ross x Ross 508 male (Kidd \& Fancher, 2001) and the Avian $34 \times$ Avian male (Kidd et al., 1998). Carcass traits in the former studies were also improved by early dietary lysine. It was concluded that optimum performance was obtained when birds were fed high dietary lysine levels not only during the starter period, but when 
increasing lysine levels were maintained in subsequent feeding phases. Feeding aggressive dietary lysine when the bird is young and feed intake is low may prove beneficial and economically advantageous provided breast meat accretion is heightened at processing.

There has been, however, little research evaluating the effect of increased dietary lysine during the starter phase on live performance and carcass traits of female broilers. If effects were to occur it could be due to the broiler strain employed (i.e. early versus late developing bird). Since the level of dietary lysine in starter diets is known to affect live performance, carcass and breast meat yield of late-finishing broilers, this study was conducted to determine if such effects are sustained in female broilers across varying genetic strain crosses.

\section{MATERIALS AND METHODS}

\section{Bird Husbandry and Experimental Facility}

Commercial female day-old chicks from three different commercial strains were obtained from an experimental hatchery. All strains were slow-feathering types; the first strain (A) can be defined as a multipurpose and early developing broiler, while the two remaining strains ( $B \& C$ ) were high-yield birds with late developing characteristics. All strains were hatched from the same hatchery and received in-ovo vaccination for Marek's disease at $18 \mathrm{~d}$ of incubation. In addition, all chicks were vaccinated for Newcastle and infectious bronchitis at $1 \mathrm{~d}$ of age via coarse spray. Upon arrival at Poultry Science Research Farm at Mississippi State University all broilers were neck-banded and randomly allocated into floor pens.

Chicks were randomly allocated to 48 pens of a closed-curtain sided house with negative pressure ventilation (10 chicks per pen; $0.10 \mathrm{~m}^{2} / \mathrm{bird}$ ). The house had thermostatically controlled heating and ventilation. Each pen had a nipple line with 3 nipples and a tube feeder. Supplemental feed pans were provided during the first five days post-hatch to ensure appropriate feed consumption. Birds had free access to feed and water. The lighting regimen consisted of 23 hours of light and 1 hour of darkness. Environmental temperature was regulated to provide thermoneutral conditions.

\section{Diets}

Feed ingredients used during the study were analyzed for bound-protein amino acid content (Llames \& Fontaine, 1994). Upon formulation and mixing, starter experimental diets were re-analyzed for supplemented dietary lysine (Llames \& Fontaine, 1994). Dietary treatments consisted of two lysine levels ( 8 pens per treatment) administered during the starter phase ( 0 to $21 \mathrm{~d}$ ) in mash form. The basal diet had a lysine level formulated to be at $1.20 \%$ while the additional diet had a lysine level of $1.35 \%$, supplemented in the form of L-Lysine- $\mathrm{HCl}$ at the expense of an inert filler (sand). Diets were composed primarily of corn and soybean meal, and all other essential amino acids were formulated to be at least at 05\% of NRC (1994) recommendations (Table 1). Common grower (21-41d) and finisher (41-56d) diets were fed to all birds in mash form, and were formulated to meet NRC (1994) recommendations. Throughout the study all birds consumed feed and water ad-libitum.

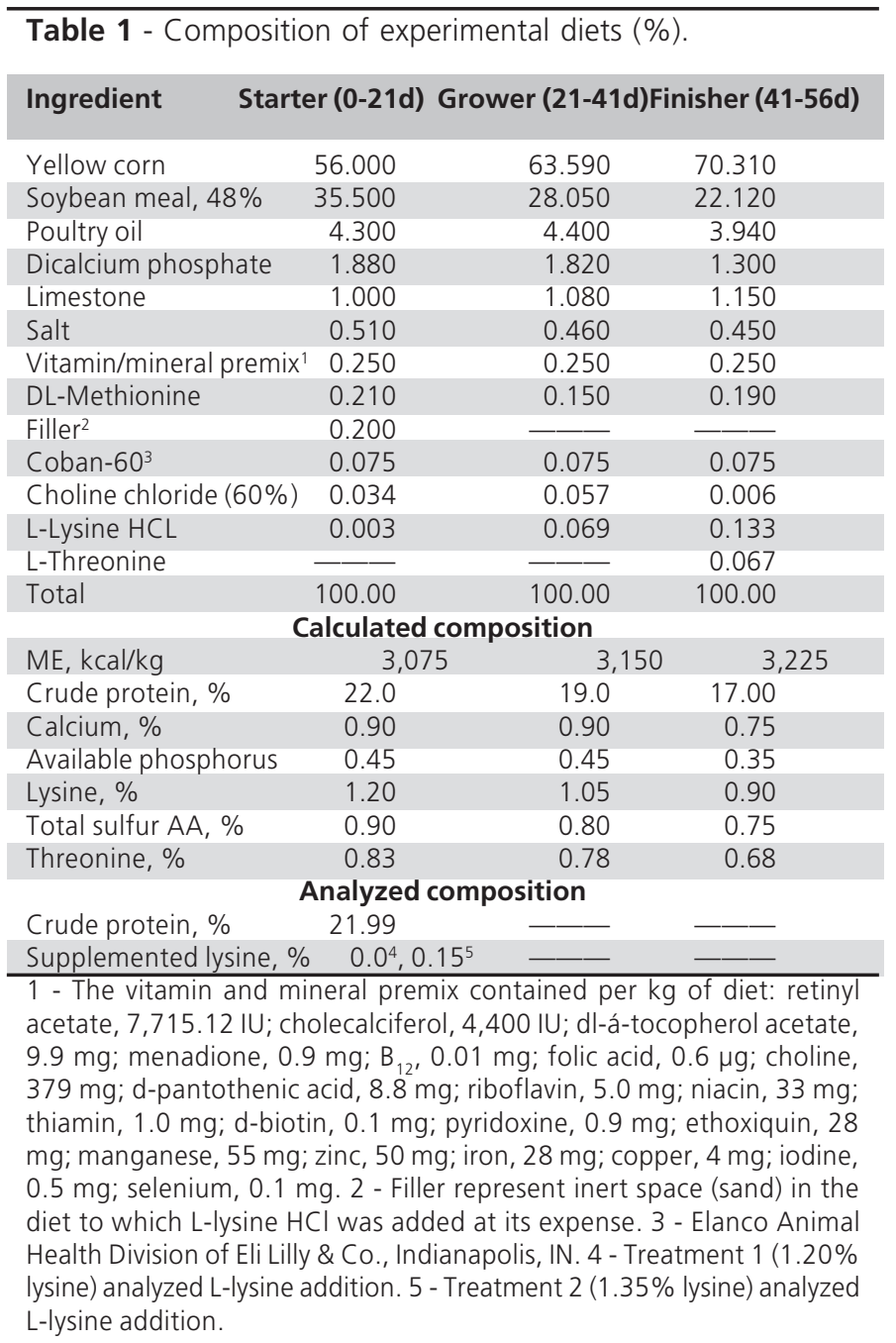

\section{Measurements and Statistical Analysis}

Pen weights and feed consumption values were obtained at 1, 21, 41, and $56 \mathrm{~d}$. The weight of birds that died was recorded daily and used to correct feed 
consumption data. Feed conversion was corrected for mortality. Measurements from 0 to 21,0 to 41 , and 0 to $56 \mathrm{~d}$ included body weight (BW), feed consumption, feed conversion, and livability. Three and remaining birds (approx. 6) from each pen were selected at random at Days 41 and 56, respectively, placed into transportation coops, and held $2 \mathrm{~h}$ prior to processing at the pilot processing plant. Broilers were stunned with an electric knife, bled for 2 min, scalded for an additional $2 \mathrm{~min}$, and then defeathered in a rotary picker. Shanks and heads were removed prior to hanging on the processing line. Remaining pin feathers were singed with flames, followed by a wash. Viscera were manually removed, and then abdominal fat and hot carcass weights were recorded. Carcasses were then transferred back to the processing line for an additional wash, followed by submersion into slush-ice containers where they remained for $4 \mathrm{~h}$. Carcasses were then pulled out and taken to a deboning line where both pectoralis major and minor muscles were manually removed and weights recorded.

All data were analyzed as a completely randomized design by the general linear models procedure of SAS (1996). Two-way interactions for the main contrasts as well as their main effects were tested. Differences among means $(p<0.05)$ were separated with repeated t-test using the LSMEANS procedure of SAS (1996).

\section{RESULTS AND DISCUSSION}

Analysis of supplemented lysine levels were as expected (Table 1, footnote). Environmental conditions were favorable throughout the study, characterized by a low incidence of mortality (Table 2 ). In contrast with previously reported findings (Kidd et al., 1998; Latshaw, 1993), this study did not exhibit elevated mortality with increasing dietary lysine levels. The differences in mortality noted from previous research concerned with variations of lysine in the starter period (Kidd et al., 1998) may have been due to gender and environmental differences.

Performance at the end of the starter feeding phase (Day 21) showed no differences between birds consuming the lysine diets, or between strains crosses. It was not until the end of the grower phase (Day 41) that differences occurred. Even though there were no differences among strain crosses for live performance and carcass trait measurements, birds consuming the high lysine starter diet had higher BW and feed intake. Feed conversion, however, was similar for all treatments.

In parallel with BW, carcass and breast meat weights were higher when birds had consumed the high lysine diet (Table 3); however, such improvement did not have any effect on their respective yields. An interaction with increasing amounts of abdominal fat deposition at $41 \mathrm{~d}$ was observed for most strains when high lysine was fed, with the exception of strain A, which tended to have a lower content of abdominal fat. However, proportion of fat relative to the carcass was similar between all treatments. Overall, performance at Day 41 resulted in no major differences among strain crosses.

Improvements in absolute body weight, carcass, and breast meat weights for birds fed the high lysine starter diet may have occurred in part due to a higher feed consumption. In spite of this, feed consumption during the starter phase was similar between the two lysine treatments. Perhaps such differences in feed intake that only happened during the grower and not the starter

Table 2 - Effects of strain cross and starter-lysine level on BW, feed intake, feed conversion, and livability of female broilers at 21, 41 and $56 \mathrm{~d}$ of age.

\begin{tabular}{|c|c|c|c|c|c|c|c|c|c|c|c|c|c|}
\hline \multirow[b]{2}{*}{ Strain } & \multirow[b]{2}{*}{ Lysine \% } & \multicolumn{3}{|c|}{ BW $(g)^{1}$} & \multicolumn{3}{|c|}{ Feed consumption (g) } & \multicolumn{3}{|c|}{ Feed:gain² } & \multicolumn{3}{|c|}{ Livability (\%) } \\
\hline & & $21 d$ & $41 \mathrm{~d}$ & $56 \mathrm{~d}$ & $0-21 d$ & $0-41 d$ & $0-56 d$ & $0-21 d$ & $0-41 d$ & $0-56 d$ & $0-21 d$ & $0-41 d$ & $0-56 d$ \\
\hline & 1.35 & 582 & $1,750^{A}$ & $2,710^{A}$ & 803 & $3,207^{\mathrm{A}}$ & $5,726^{A}$ & 1.38 & 1.84 & 2.12 & 97.2 & 95.0 & 94.9 \\
\hline & 1.20 & 567 & $1,675^{\mathrm{B}}$ & $2,632^{B}$ & 777 & $3,046^{B}$ & $5,491^{B}$ & 1.37 & 1.82 & 2.09 & 97.1 & 96.6 & 96.6 \\
\hline$A$ & 1.35 & 586 & 1,736 & 2,699 & 785 & 3,229 & 5,714 & 1.33 & 1.88 & 2.12 & 97.2 & 94.5 & 94.5 \\
\hline A & 1.20 & 590 & 1,709 & 2,640 & 795 & 3,125 & 5,573 & 1.35 & 1.83 & 2.11 & 97.5 & 97.3 & 97.3 \\
\hline B & 1.35 & 574 & 1,750 & 2,750 & 809 & 3,197 & 5,855 & 1.41 & 1.83 & 2.13 & 97.2 & 94.3 & 94.1 \\
\hline B & 1.20 & 563 & 1,675 & 2,628 & 758 & 2,976 & 5,436 & 1.34 & 1.78 & 2.07 & 96.4 & 95.7 & 95.7 \\
\hline C & 1.35 & 585 & 1,765 & 2,682 & 816 & 3,194 & 5,608 & 1.39 & 1.82 & 2.09 & 97.3 & 96.3 & 96.3 \\
\hline C & 1.20 & 549 & 1,642 & 2,630 & 777 & 3,038 & 5,464 & 1.42 & 1.86 & 2.08 & 97.5 & 96.9 & 96.9 \\
\hline \multicolumn{5}{|c|}{ Source of Variance } & \multicolumn{6}{|c|}{ Probability } & & & \\
\hline \multicolumn{2}{|l|}{ Strain } & 0.08 & 0.86 & 0.72 & 0.84 & 0.28 & 0.37 & 0.29 & 0.53 & 0.68 & 0.94 & 0.81 & 0.83 \\
\hline \multicolumn{2}{|l|}{ Lysine } & 0.09 & 0.01 & 0.02 & 0.16 & 0.01 & 0.01 & 0.85 & 0.53 & 0.38 & 0.96 & 0.42 & 0.49 \\
\hline \multicolumn{2}{|c|}{ Strain $x$ Lysine } & 0.18 & 0.40 & 0.64 & 0.38 & 0.58 & 0.20 & 0.59 & 0.57 & 0.80 & 0.94 & 0.90 & 0.91 \\
\hline \multicolumn{2}{|l|}{ SEM } & 10.2 & 34.9 & 40.7 & 22.9 & 56.2 & 87.3 & 0.060 & 0.055 & 0.039 & 0.92 & 1.31 & 1.30 \\
\hline
\end{tabular}

1 - Values within comparisons with different superscripts differ ( $p=0.05) .2$ - Values adjusted for mortality. 


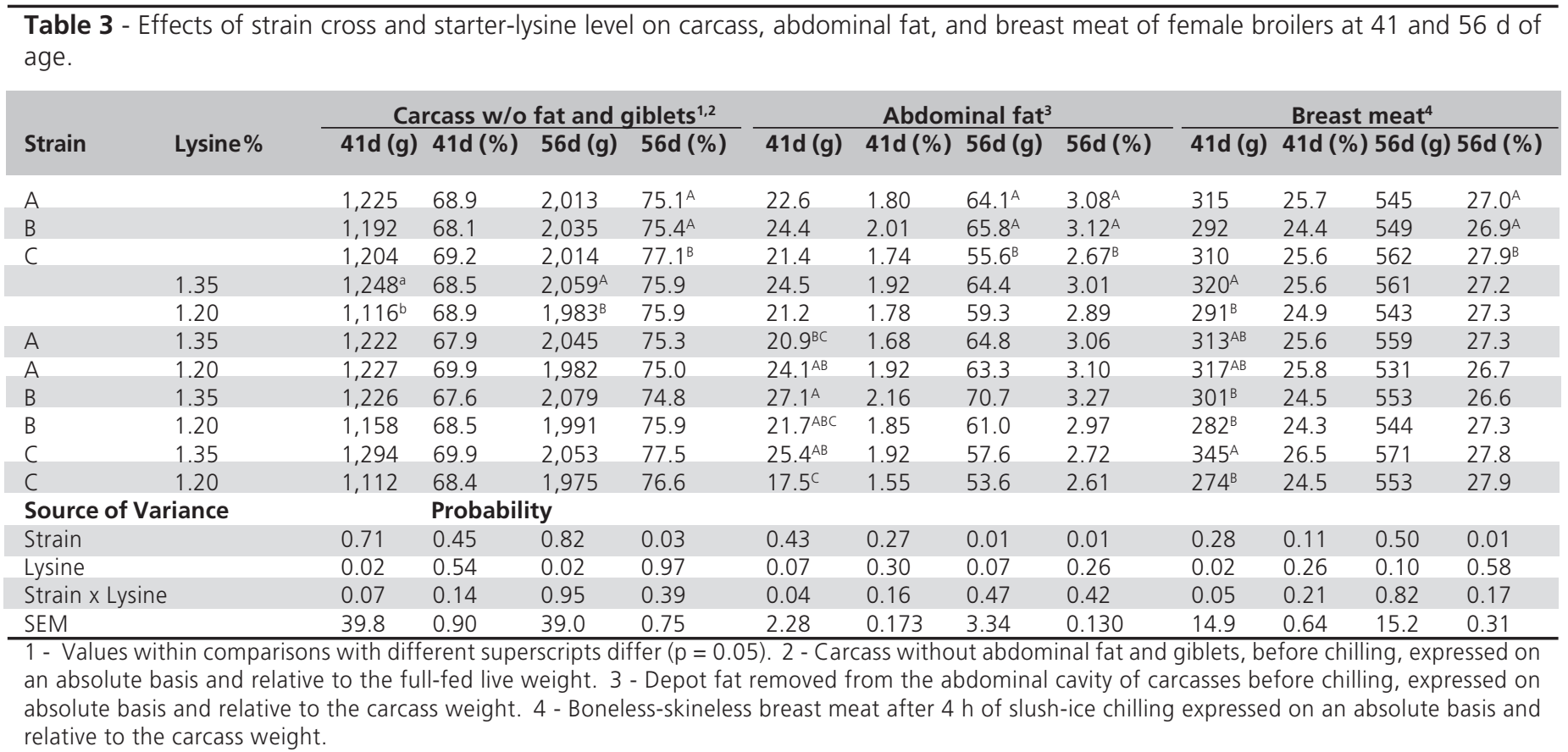

phase could be attributed to the birds' attempt to compensate for the drastic reduction in lysine density experienced when feed was replaced from the starter to the grower phase; such effect could be due to a higher need to maintain and support the accelerated lean tissue growth stimulated by the high lysine starter phase feed.

At the end of the finisher phase (Day 56) feed consumption was still higher for birds that consumed the high lysine diet during the starter phase. In turn, BW remained higher in birds that received high-lysinestarter diets, replicating what occurred at the end of the grower phase. Carcass weight of high-lysine birds exhibited the same effect that occurred at $41 d$, but breast meat even though numerically was not statistically superior. Strain $C$ displayed higher carcass and breast meat yields when compared to the other two strains, and also a reduction in absolute and relative abdominal fat depot. Explanation for such improvement only at Day 56 can be attributed to the characteristics of the strain, which is classified as a late-developing line.

Findings in the present experimentation did not reflect those observed with Ross 508 males (Kidd \& Fancher, 2001) and Avian 34 males (Kidd et al., 1998); perhaps the use of females, because of their genetic predisposition to accrete more relative body fat than males, diminishes the potential for improvement in yield parameters with early lysine fortification. Nevertheless, further research is warranted in order to validate present findings. Furthermore, poultry companies should consider potential advantages of early lysine supplementation above recommended levels in order to maximize absolute weights of broilers and carcass traits while concomitantly minimizing cost relative to labor employed per pound of final product. Evidently, existing differences between male and female broilers with early lysine supplementation may provide a considerable advantage to nutritionists in order to reduce costs associated with feed, particularly if the two genders are fed separately.

\section{REFERENCES}

Han Y, Baker DH. Lysine requirement of fast and slow growing broiler chicks. Poultry Science 1991; 70:2108-2114.

Han Y, Baker DH. 1993. Effect of sex, heat stress, body weight and genetic strain on the lysine requirement of broiler chicks. Poultry Science 1993; 72:701-708.

Hewitt $D$, Lewis $D$. The amino acid requirements of the growing chick. 1. Determination of amino acid requirements. British Poultry Science 1972; 13:449-463.

Kidd MT, Fancher BI. Lysine needs of starting chicks and subsequent effect during the growing period. Journal of Applied Poultry Research 2001; 10:385-393.

Kidd MT, Kerr BJ, Halpin KM, McWard GW, Quarles CL. Lysine levels in starter and grower-finisher diets affect broiler performance and carcass traits. Journal of Applied Poultry Research 1998; 7:351-358. 
Llames CR, Fontaine J. Determination of amino acids in feeds: Collaborative Study. Journal of AOAC International 1994; 77:13621402.

Latshaw JD. Dietary lysine concentrations from deficient to excessive and the effects on broiler chicks. British Poultry Science 1993; 34:951-958.

McNaughton JL, May JD, Reece FN, Deaton JW. Lysine requirement of broilers as influenced by environmental temperatures. Poultry Science 1977; 56:57-64.

National Research Council. 1994. Nutrient Requirements of Poultry. $9^{\text {th }}$ rev. ed. National Academy Press, Washington, DC, USA.

SAS Institute. 1996. User's Guide:Statistics Version 7.0. SAS Institute, Inc., Cary, NC, USA.

Schwartz, HG, Taylor MW, Fisher H. The effect of dietary energy concentration and age on the lysine requirement of growing chicks. Journal of Nutrition 1958; 65:25-37.

Vasquez M, Pest GM. Estimation of the lysine requirement of broiler chicks for maximum body gain and feed efficiency. Journal of Applied Poultry Research 1997; 6:241-246. 


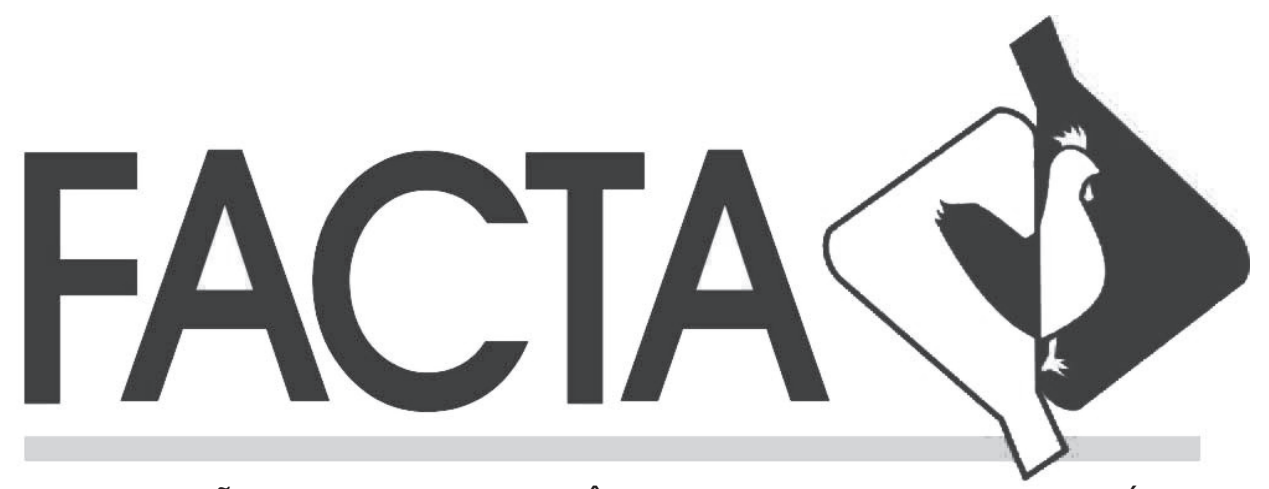

FUNDAÇÃO APINCO DE CIÊNCIA E TECNOLOGIA AVÍCOLAS

\section{CONFERÊNCIA APINCO'2005}

Data: Maio de 2005

Local: Mendes Convention Center

Santos - São Paulo - Brasil 